\title{
Study of the Processes of Electroosmotic Cleaning of Soils from Oil Pollution on a Three- dimensional Physical Model
}

\author{
Evgeniy Shabanov ${ }^{1}$ \\ ${ }^{1}$ T.F. Gorbachev Kuzbass State Technical University, Str. Vesennyaya, 28, Kemerovo, Russian \\ Federation, 650000
}

\begin{abstract}
The methods and results of laboratory modeling of processes in clay soils contaminated with oily substances are reviewed: on samples, on one-dimensional and three-dimensional physical models. Laboratory facilities, the procedure for conducting experiments and processing their results are described. The possibility of a point and integral forecast of the degree of soil contamination by the results of measurements of its electrical resistance is confirmed. The dynamics of changes in porosity, humidity, and particle size distribution of oil-contaminated soils during electric treatment as a result of thermal and osmotic effects by comparing direct measurement data and electrophysical monitoring using a system of micro-sensors was revealed. A comparison of the results of the electric treatment of clean soil, contaminated with liquid and viscous oil products is given.
\end{abstract}

\section{Introduction}

One of the most common pollutants is oil and petroleum products. Accidents at oil producing enterprises during the transportation of oil lead to disastrous consequences. In the absence of emergency situations, oil pollution of soils occurs in mass volumes. So, in the mining and coal processing enterprises of Kuzbass, such events occur at stationary and mobile fuel and oil filling stations, fuel and lubricant warehouses, and a significant number of contaminations occur in the soil foundations of existing buildings and structures, which complicates or eliminates their mechanical removal for decontamination [1].

Methodological approaches to solving the problem of soil cleaning from contamination are considered in the fundamental monograph [2]. Modern studies conducted by various organizations are aimed at the development of physicochemical [3, 4], biological $[5,6,7]$ decontamination methods or their combination $[8,9]$. At the same time, it is emphasized that with the exposure to point (local) sources of pollutant emission the importance of monitoring methods increases (location of pollution zones, control of changes in the concentration of ecotoxicant) [10,11].

Promising is the application of the electrochemical method used in deactivating treatment of low-permeable soils, combining high-density current passing through soil, electroosmotic saturation of soils with an active liquid, dilution of viscous components or deactivation of the pollutant, and removal of solutions containing dissolved pollutant. The experimental and theoretical foundations of electroosmotic processes described in [12] have found practical application in land reclamation (drawdown and dewatering) and construc- 
tion (consolidation of soil with chemical solutions). Due to the complexity and insufficient knowledge of a number of physical and chemical processes that occur during electric treatment, as well as the energy intensity of this method, it has not yet become a frequent practice.

The idea of using the electrochemical method for cleaning soils from oil pollutants and other ecotoxicants is being developed at Moscow State University under the guidance of Professor V. A. Korolyov. The results of fundamental studies of electrosurface phenomena in clayey rock proved the practical significance of this research line [13-15].

Another unsolved problem is the control of processes of soil treatment at its various stages; this area of research is being developed in the Geocontrol Laboratory of KuzSTU.

\section{Method of research}

To identify patterns of changes in the physical properties of soil during electroosmotic cleaning up from oil pollution, the studies were conducted in the laboratory of KuzSTU on the experimental installation, the scheme of which is shown in Fig. 1.

The main objectives of the experimental studies were as follows:

- Study the change patterns in the physical properties of soil during electroosmotic cleaning up from oil pollution;

- Study the physical parameters of the soil being cleaned;

- Study electrocoagulation processes that contribute to the transition of petroleum products into a solid state.

The physical model is a section of the electrochemical cleaning zone with the actual dimensions of the electrodes and the distance between them in a horizontal section. As the test medium, compacted loam mixed with a mixer with oil was used. The concentration of the oil contaminant corresponded to what was practically possible during gradual pollution or during an oil spill as a result of an accident. Thus, none of the physical parameters of the model differed from the corresponding parameters of nature.

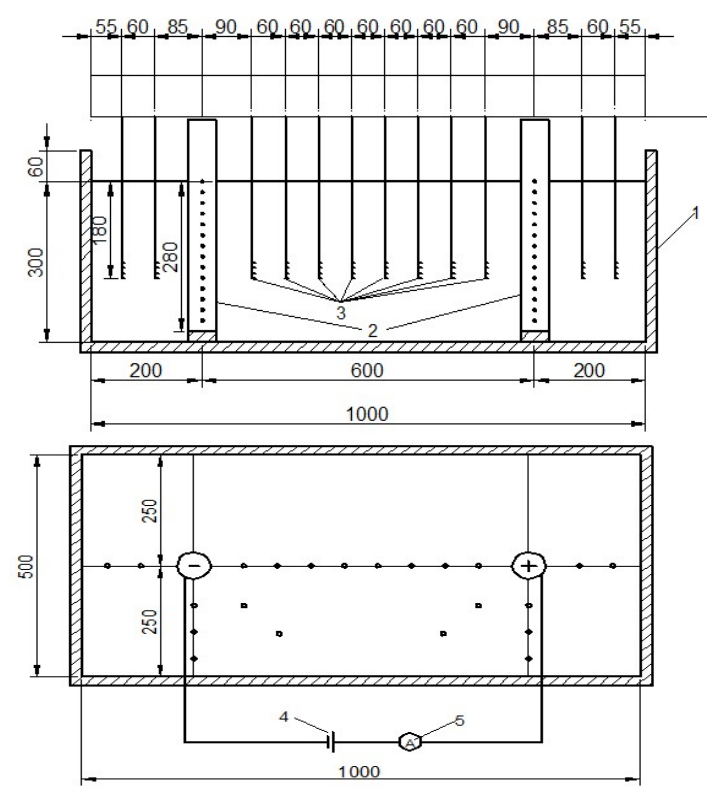

Fig. 1. Scheme of the experimental model: 1 - bath; 2 - electrodes; 3 - microprobe sensors; 4 - feeding installation (two DC power sources); 5 - ammeter. 
A bathtub of $1000 \times 500 \times 360 \mathrm{~mm}$ in size is made of a non-conductive material - laminated, moisture-proof plywood, waterproofed with a plastic film and filled with loam. Electrodes made in the form of perforated steel electric-welded tubes with an inner diameter of $51 \mathrm{~mm}$ blanked off at the bottom with a wooden plug were immersed in the soil to a depth of $300 \mathrm{~mm}$.

The experimental technique included the measurement of the electrical resistivity of contaminated soil with the help of probes made of four-core copper cable. Microprobe sensors with a contact spacing of $\mathrm{AM}=\mathrm{MN}=\mathrm{NB}=10 \mathrm{~mm}$ are immersed in soil to a depth of $180 \mathrm{~mm}$. The total number of sensors is 22 . The measuring device is a KP-2 logging tool that implements direct current resistivity measurements in pulsed mode with automatic polarization compensation developed at KuzSTU. The remaining electrical characteristics of the soil and installation were measured with a MY64 electronic multimeter. The electric field in the model was created by a stabilized power supply unit with a voltage of $U=50$ $300 \mathrm{~V}$, with a current strength of up to $0.6 \mathrm{~A}$. Graphs of changes in the relative electrical resistivity along the main axis of the electric treatment at its various stages are shown in Figs. 2 and 3.

The physico-mechanical characteristics of the soil were determined using the following instruments and accessories of the PLL-2 field laboratory: a set of sample bottles for determining moisture, an electronic balance, an oven, a set of sieves.

At the first stage of the experiment, two baths were processed in parallel. The first was loaded with pure clay loam weighing $260 \mathrm{~kg}$, mixed with water (52) kg, and the second was loaded with clay loam weighing $250 \mathrm{~kg}$, mixed with water $(47 \mathrm{~kg})$ and waste oil as an oil contaminant $(8.1 \mathrm{~kg})$.

\section{Results and Discussion}

From the above experimental results, it follows that the electroosmotic processes in the near-electrode regions during the processing of clean and oil-contaminated soil are interrelated and have significant differences due to the difference in the electrically conductive properties of the aqueous solution (low resistivity) and machine oil (dielectric):

- in pure soil (Fig. 2), a progressive movement of moisture from the cathode to the anode occurs, accompanied by a decrease in resistivity in the zone of moisture accumulation and an increase in resistivity in the electric drying zone, while the anode drainage zone exceeds the moisture saturation zone along the length of the water, and the formation of these zones occurs sufficiently quickly, 30-35 A hours from the start of electric treatment;

- in the contaminated soil (Fig. 3), the wave-like nature of the change in resistivity is recorded, due to the fact that the viscosity of the oil is much higher than that of the aqueous solution, while the positive peaks of resistivity, corresponding to the predominance in the pores of the oil product, and negative, corresponding to the predominance of the aqueous solution, become more contrasting and move to the anode zone; in the cathode region during the outflow of moisture, the electrical resistivity changes insignificantly, which indicates the predominant effect on the insulation of mineral soil grains with an oil film. 


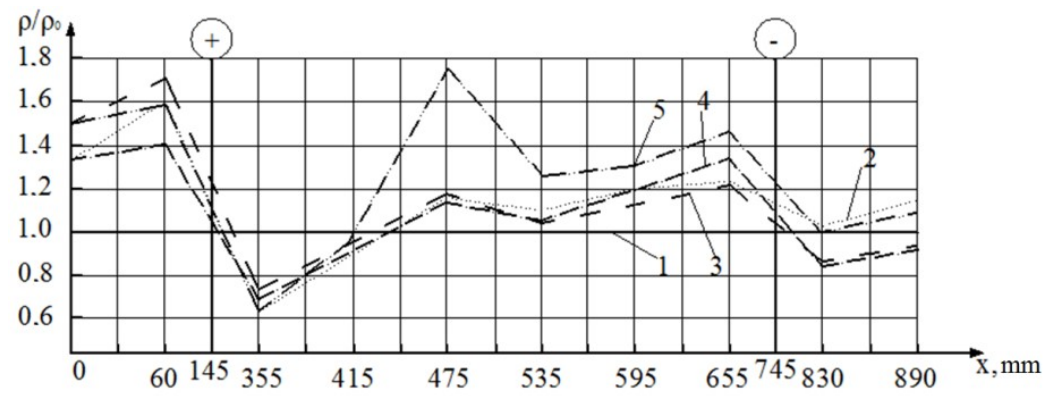

Fig. 2. The change in the resistivity of clean soil during electrochemical treatment: 1 - start of treatment; 2 - after $3.6 \mathrm{~A} \cdot \mathrm{h} ; 3$ - $6 \mathrm{~A} \cdot \mathrm{h} ; 4$ - $13.5 \mathrm{~A} \cdot \mathrm{h} ; 5$ - $22.5 \mathrm{~A} \cdot \mathrm{h}$.

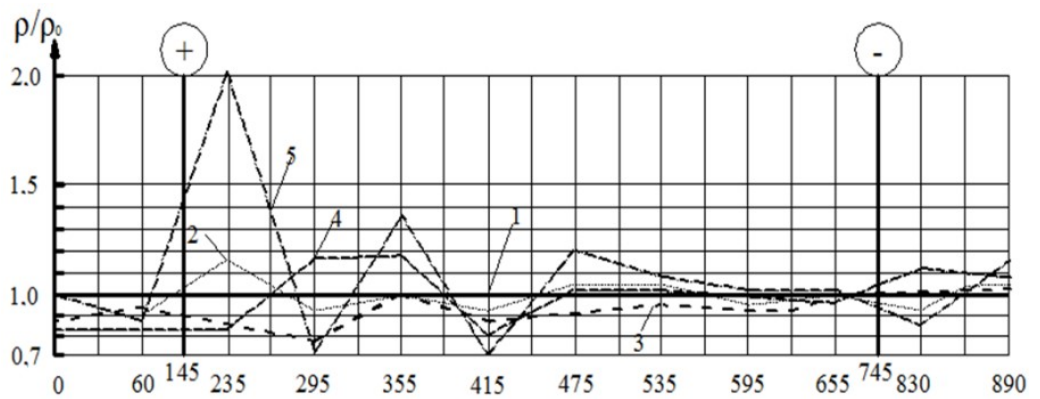

Fig. 3. Changes in electrical resistivity of soil contaminated with SHELL HELIX waste oil during electrochemical treatment: 1 - start of treatment; 2 - after $10 \mathrm{~A} \cdot \mathrm{h} ; 3$ - $30.3 \mathrm{~A} \cdot \mathrm{h} ; 4$ - $50.7 \mathrm{~A} \cdot \mathrm{h} ; 5$ - 65.1 A.h.

Hydrodynamic processes in the near-electrode regions are characterized by circular resistivity diagrams shown in Figs. 4 and 5.

The following features of the formation of near-electrode volume zones are established:

- around the anode in clean soil there is an asymmetry of resistivity, a zone of moisture accumulation with $P / \rho_{0}=0.6-0.7$ corresponds to a circular sector in the range $\Delta \varphi=90-120^{\circ}$, from the lateral and reverse directions the outflow of fluid is recorded; a zone of thermal drainage of the soil is formed immediately near the cathode electrode $(\mathrm{r}=$ $90 \mathrm{~mm}$ ), but as the distance from the axis of the electrode increases, the anisotropy of the electrical resistivity is significantly smoothed;

- in a contaminated soil in the cathode zone, a pronounced layer of thermal drainage is not fixed, otherwise the structure of this zone does not differ from the clean soil; in the anode volume, the oil product accumulation sector reaches $\Delta \varphi=180^{\circ}$. 

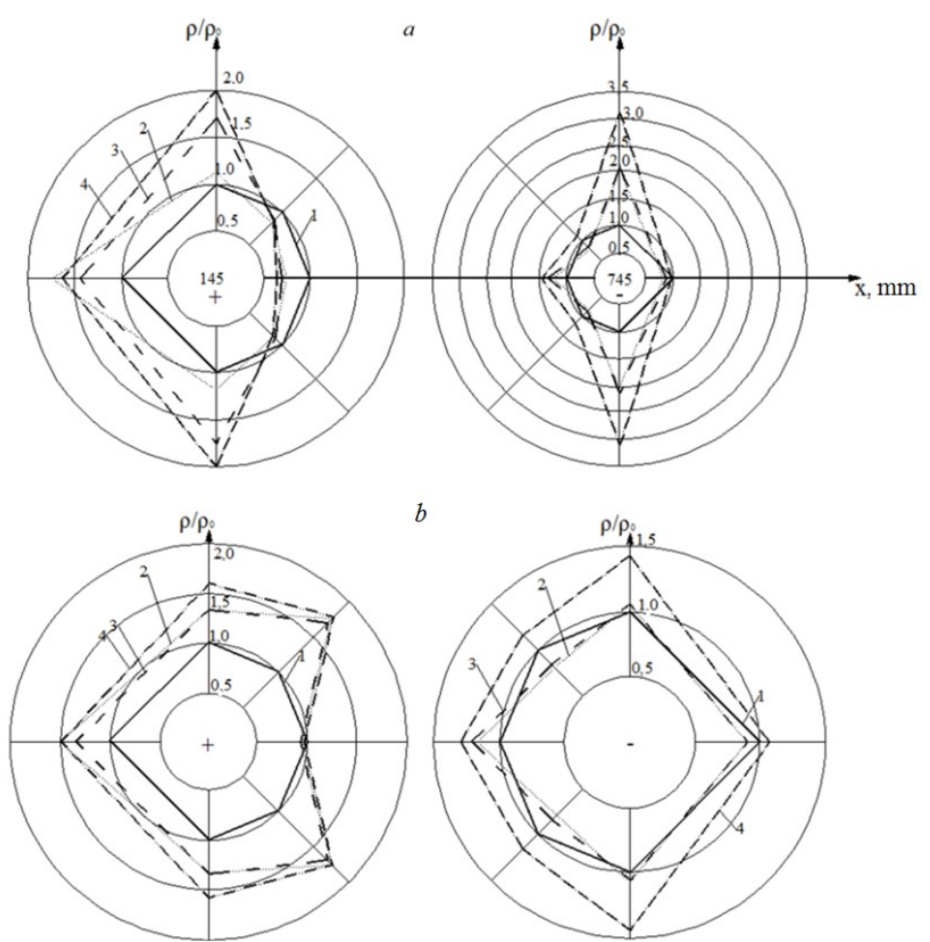

Fig. 4. Pie charts of changes in the resistivity of clean soil during electrochemical treatment at $\mathrm{r}=$ $90 \mathrm{~mm}$ (a) and $\mathrm{r}=150 \mathrm{~mm}$ (b): 1 - start of treatment; 2 - $6 \mathrm{~A} \cdot \mathrm{h} ; 3-13.5 \mathrm{~A} \cdot \mathrm{h} ; 4-22.5 \mathrm{~A} \cdot \mathrm{h}$.
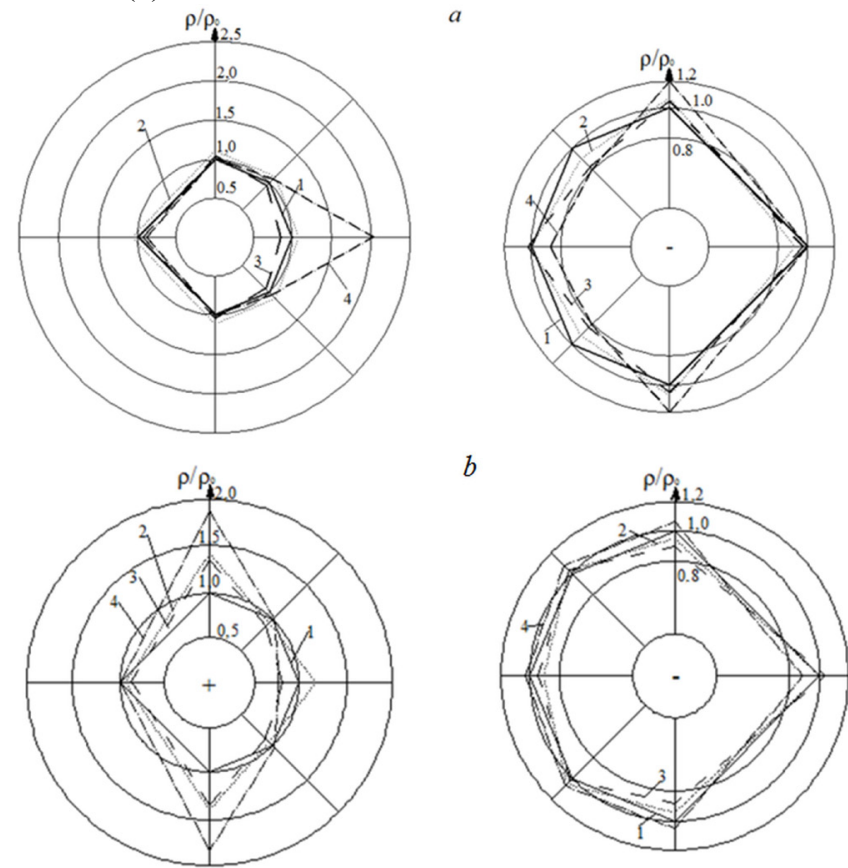

$b$

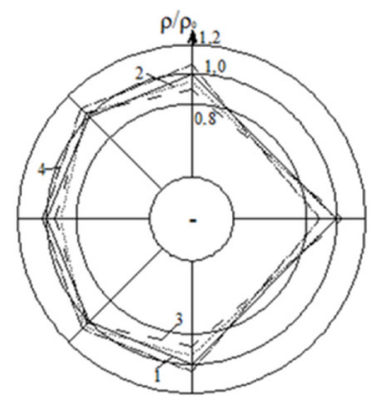

Fig. 5. Pie charts of changes in resistivity of soil contaminated with waste oil during electrochemical treatment at $\mathrm{r}=90 \mathrm{~mm}$ (a) and $\mathrm{r}=150 \mathrm{~mm}$ (b): 1 - start of treatment; 2 - $21.3 \mathrm{~A} \cdot \mathrm{h} ; 3$ - $30.3 \mathrm{~A} \cdot \mathrm{h} ; 4$ $65.1 \mathrm{~A} \cdot \mathrm{h}$.

The uniformity of the processes described above in the near-electrode regions on the 
main processing axis is characterized by the dependences of the relative resistivity $P / P_{0}$ at characteristic points of the soil on the current consumption I't, shown in Fig. 6.
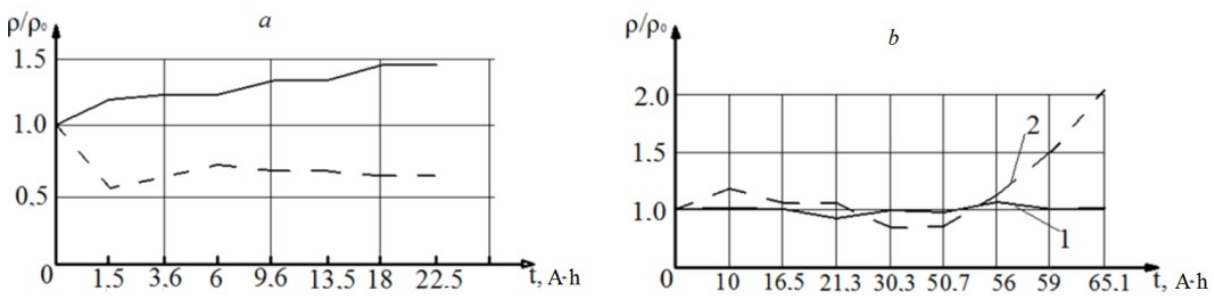

Fig. 6. Changes in the resistivity of clean soil (a) and soil contaminated with SHELL HELIX (b) waste oil during electrochemical treatment: 1 - on sensor \#1 near the negative electrode; 2 - on sensor \#8 near the positive electrode.

The results of studies of the physical properties of the soil before and after treatment are given in Table 1, and the particle size distribution of the soil is shown in Table 2 and in Fig. 7

Table 1. The change in the physical parameters of the soil as a result of electric treatment.

\begin{tabular}{|l|l|l|l|}
\hline \multirow{2}{*}{$\begin{array}{l}\text { Bath \# } \\
\text { sample location }\end{array}$} & \multicolumn{3}{|c|}{ Characteristics (before / after treatment) } \\
\cline { 2 - 4 } & $\begin{array}{l}\text { Humidity, } \\
\%\end{array}$ & $\begin{array}{l}\text { Density in wet } \\
\text { condition, } \mathrm{g} / \mathrm{sm}^{3}\end{array}$ & $\begin{array}{l}\text { Density in dry } \\
\text { condition, } \mathrm{g} / \mathrm{sm}^{3}\end{array}$ \\
\hline$\# 1$ on the positive electrode & $35.3 / 28.1$ & $2.38 / 2.22$ & $1.76 / 1.728$ \\
\hline$\# 1$ in the middle & $35.2 / 30.1$ & $2.33 / 2.20$ & $1.73 / 1.694$ \\
\hline \# on the negative electrode & $35.2 / 29.6$ & $2.14 / 2.01$ & $1.58 / 1.550$ \\
\hline$\# 2$ on the positive electrode & $39.4 / 29.1$ & $2.51 / 2.28$ & $1.80 / 1.766$ \\
\hline$\#$ 2 in the middle & $39.4 / 31.3$ & $2.48 / 2.23$ & $1.78 / 1.746$ \\
\hline$\# 2$ on the negative electrode & $39.4 / 28.8$ & $2.44 / 2.22$ & $1.75 / 1.720$ \\
\hline
\end{tabular}

Table 2. Change in the particle size distribution of the soil as a result of electric treatment.

\begin{tabular}{|l|l|l|l|l|l|}
\hline \multirow{2}{*}{$\begin{array}{l}\text { Bath \# } \\
\text { sample location }\end{array}$} & \multicolumn{5}{|l|}{ The content of fractions (in m),\% (before / after treatment) } \\
\cline { 2 - 6 } & 2 & 0.5 & 0.25 & 0.1 & $<0.1$ \\
\hline \# 1 on the positive electrode & $8.8 / 12.0$ & $33.3 / 36.0$ & $17.5 / 15.0$ & $19.2 / 19.0$ & $21.2 / 18.0$ \\
\hline$\# 1$ in the middle & $8.8 / 9.8$ & $33.3 / 34.1$ & $17.5 / 16.2$ & $19.2 / 23.0$ & $21.2 / 16.9$ \\
\hline$\# 1$ on the negative electrode & $8.8 / 9.5$ & $33.3 / 37.2$ & $17.5 / 15.7$ & $19.2 / 22.0$ & $21.2 / 15.6$ \\
\hline$\# 2$ on the positive electrode & $8.8 / 6.1$ & $33.3 / 41.8$ & $17.5 / 15.8$ & $19.2 / 31.2$ & $21.2 / 5.1$ \\
\hline$\# 2$ in the middle & $8.8 / 7.3$ & $33.3 / 38.2$ & $17.5 / 16.3$ & $19.2 / 26.2$ & $21.2 / 12.0$ \\
\hline$\# 2$ on the negative electrode & $8.8 / 8.6$ & $33.3 / 43.7$ & $17.5 / 14.5$ & $19.2 / 24.8$ & $21.2 / 8.4$ \\
\hline
\end{tabular}
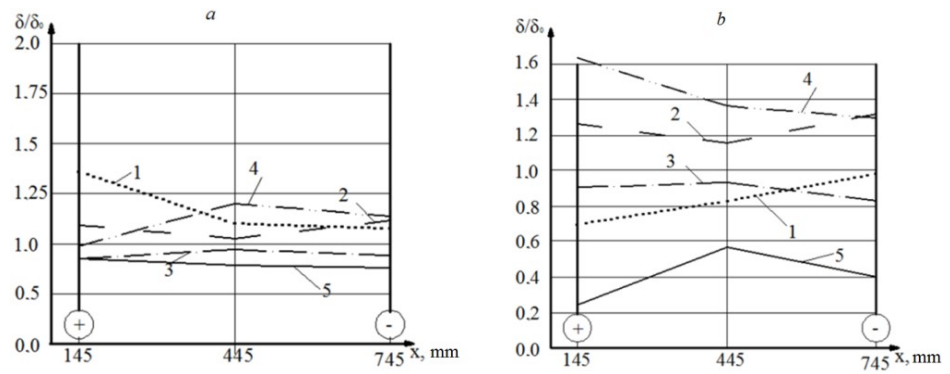

Fig. 7. Change in particle size distribution of clean (a) and contaminated (b) soil during electrochemical treatment: 1 - fraction $2 \mathrm{~mm} ; 2-0.5 \mathrm{~mm} ; 3-0.25 \mathrm{~mm} ; 4-0.1 \mathrm{~mm} ; 5-<0.1 \mathrm{~mm}$. 
From the data in Table 1 it follows that in both soils during electrical treatment, chemical bonding of moisture and oil product occurs, which leads to a general decrease in soil moisture by $5-20 \%$ and a decrease in its density by $2-10 \%$ in both wet and dry conditions.

Very significant changes are established in the particle size distribution of the soil:

- in clean soil, only in the anode zone, a sharp decrease in the content of the fraction $<0.1 \mathrm{~mm}$ and an increase in the fraction of $2.0 \mathrm{~mm}$ were established;

- in contaminated soil throughout the treatment area there is an increase in particle size with the transition of the fraction $<0.1 \mathrm{~mm}$ to the range $0.1-0.5 \mathrm{~mm}$ due to oil coagulation processes; sticking of small particles together, while the transition of the oil product from a liquid to a solid state is probable, which is considered less toxic and environmentally harmful.

\section{Conclusion}

An analysis of the results allowed us to draw the following conclusions:

- when an electric current is passed and oil products in the soil pores are exposed to it, they turn into a solid cohesive state, which leads to an increase in resistivity of the soil throughout the treatment area, as well as to a decrease in humidity;

- as a result of the electrolytic effect of direct current on the contaminated soil, the formation of solid particles and the adhesion of these particles occur, which leads to a change in the particle size distribution of clay soil in the direction of increasing the content of larger fractions;

- when treating soil with electric current, soil moisture decreases, and an increase in the percentage of large fractions leads to a decrease in soil density, both in wet and in dry condition;

- the process of phase transformation of an oily product in the soil pores due to electrical and thermal coagulation occurs throughout the inter-electrode space.

The study was conducted as part of grant MK-1212.2020.5 "Geological and geophysical monitoring of the processes of electrochemical cleaning of soil bases of structures from oil pollution".

\section{References}

1. M. Cehlár, J. Janočko, Z. Šimková, T. Pavlik, M. Tyulenev, S. Zhironkin, M. Gasanov, Resources, 8, 1, 21 (2019)

2. O. K. Tiapkin, A. L. Lozovyi, A. O. Burlakova, P. H. Pihulevskyi, 18th International Conference "Geoinformatics: Theoretical and Applied Aspects", 18, 15639 (2019)

3. S. Prostov, E. Shabanov, E3S Web of Conferences, 41, 01006 (2018)

4. I. B. Archegova, F. M. Khabibullina, A. A. Shubakov, Contemporary Problems of Ecology, 6, 548 (2012)

5. V. Filipovic, V. Popovic, D. Glamoclija, M. Jaramaz, D. Jaramaz, S. Andelovic, M. Tabakovic, Bulgarian Journal of Agricultural Science, 20, 1 (2014)

6. I. V. Trusei, A. Yu. Ozerskii, V. P. Ladygina, Contemporary Problems of Ecology, 1, 22 (2009)

7. S. I. Kolesnikov, M. G. Zharkova, K. Sh. Kazeev, Russian Journal of Ecology, 3, 157 (2014)

8. V. A. Efremova, E. V. Dabakh, L. V. Kondakova, Contemporary Problems of Ecology, 5, $561(2013)$ 
9. G. Pop, E. Alexa, T. Iancu, F. Imbrea, A. Laza, Revista de Chimie, 68, 4, 776 (2017)

10. E. L. Vorobeichik, M. V. Kozlov, Russian Journal of Ecology, 2, 89 (2012)

11. V. P. Seredina, M. E. Sadykov, Contemporary Problems of Ecology, 5, 457 (2011)

12. U. Ghosh, S. Chakraborty, Physics of Fluids, 27, 6, 062004 (2015)

13. S. Prostov, E. Shabanov, E3S Web of Conferences 105, 02013 (2019)

14. E. A. Shabanov, S. M. Prostov, Coal in the 21st Century: Mining, Processing and Safety, 1, 175 (2016)

15. V. A. Korolev, O. V. Romanyukha, A. M. Abyzova, Journal of Environmental Scince and Health. Part A: Toxic/Hazardous Substances and Environmental Engineering, 43, $8,876(2008)$ 